\title{
Motivated Collective Defensiveness: Group Members Prioritize Counterarguing Out-Group Criticism Over Getting Their Work Done
}

Social Psychological and Personality Science 2019, Vol. 10(3) 382-392 (C) The Author(s) 2018 Article reuse guidelines: sagepub.com/journals-permissions DOI: 10.1 |77/| $9485506 / 8762298$ journals.sagepub.com/home/spp

(QSAGE

\author{
J. Lukas Thürmer ${ }^{1,2,3}$, Sean M. McCrea ${ }^{4}$, and Baylee M. Mclntyre ${ }^{4}$
}

\begin{abstract}
Group members defensively reject out-group criticism in self-reports because they perceive it as more threatening than the same criticism from the in-group (intergroup sensitivity effect). But does this effect motivate action? In five experiments, group members exhibited behavior patterns characteristic of motivated goal pursuit: They prioritized defending their group over completing their individual work (Experiments 1-5), even when work was intrinsically rewarding (Experiment 2) or incentivized (Experiment 3). Lastly, this effect disappeared when group members had attained their goal of protecting their group by other means (i.e., group affirmation; Experiments 4 and 5). Together, the experiments suggest that intergroup sensitivity motivates goal-directed action. We discuss how motivated collective defensiveness may undermine constructive debate and heighten acrimony between groups.
\end{abstract}

\section{Keywords}

motivation/goals, self/identity, self-defensiveness, intergroup sensitivity effect, affirmation, counterarguing

I've never seen the country so divided, just black and whitethere's no compromise whatsoever.

U.S. voter cited in the New York Times (Parker \& Corasaniti, p. A1, October 27, 2016)

Just as individuals reject threatening criticism directed at them personally, group members reject criticism directed at their group. As exemplified in the quote above, collective defensiveness can undermine constructive debate and heighten acrimony between groups. Psychological science has established a firm understanding of such collective defensiveness and its underlying processes in self-reports, but it is unclear whether collective defensiveness qualifies as motivated. In other words, does collective defensiveness lead to persistent behavior that is characteristic of ongoing goal pursuit? And, if so, what can be done to reduce this potentially costly behavior?

\section{Collective Defensiveness: The Case of the Intergroup Sensitivity Effect (ISE)}

Group members react defensively to out-group criticism. They perceive out-group criticism as more threatening and reject it more than the same criticism from an in-group member (ISE; Hornsey, 2005; Hornsey \& Esposo, 2009), and out-group sources are viewed as making their comments with less constructive intentions than in-group sources (Hornsey, Robson, Smith, Esposo, \& Sutton, 2008; Hornsey, Trembath, \& Gunthorpe, 2004). As a result, group members perceive out-group criticism as a threat to the group (de Hoog, 2013;
Study 1). Consistent with this statement, the ISE is eliminated or reversed when in-group criticism poses a high threat (Ariyanto, Hornsey, \& Gallois, 2010; Elder, Sutton, \& Douglas, 2005; Morier, Bryan, \& Kasdin, 2013). Moreover, group members even show the ISE when comments are high in quality or made by experienced out-group members (Esposo, Hornsey, \& Spoor, 2013; Hornsey \& Imani, 2004), and they also report weaker intentions to act on out-group criticism than in-group criticism (Brander \& Hornsey, 2006; see also Rabinovich \& Morton, 2010).

This consistent support for the ISE is based on self-reports or, in a few cases, measures of intentions or hypothetical decisions. Self-reports and inconsequential behaviors may not reflect actual motivations (Baumeister, Vohs, \& Funder, 2007) and even measured intentions are a poor proxy for behavior (Kruglanski et al., 2015; Sheeran \& Webb, 2016). It therefore remains unknown whether intergroup sensitivity is

\footnotetext{
I Department of Psychology, University of Konstanz, Konstanz, Germany

${ }^{2}$ Department of Political Science and Administration, University of Konstanz, Konstanz, Germany

${ }^{3}$ Department of Psychology, University of Pittsburgh, Pittsburgh, PA, USA

${ }^{4}$ Department of Psychology, University of Wyoming, Laramie, WY, USA
}

\section{Corresponding Author:}

J. Lukas Thürmer, Department of Politics and Public Administration, University of Konstanz, PO Box 87, 78457 Konstanz, Germany.

Email: lukas.thuermer@uni-konstanz.de 
motivated and results in the allocation of resources, such as time, toward defending group identity.

\section{Is Intergroup Sensitivity Motivated? Potential Behavioral Consequences}

Motivation science and social identity theory suggest that the ISE should motivate behavior. Identification with a social group motivates individuals to strive for a positive group identity (Branscombe, Ellemers, Spears, \& Doosje, 1999; Brewer \& Gardner, 1996; Sherman, Kinias, Major, Kim, \& Prenovost, 2007; Tajfel \& Turner, 1986). Striving for a positive identity is a goal (cf. Gollwitzer, Wicklund, \& Hilton, 1982), and a threat to a positive identity is an obstacle to goal attainment. Obstacles to goal attainment lead to increasing effort and allocating resources to the focal goal (Carver \& Scheier, 1990). Thus, threats to the goal of maintaining a positive social identity should result in the allocation of resources, such as time, toward defending group identity (cf. Baumeister \& Scher, 1988; Crocker \& Park, 2004). Specifically, we suggest that group members may spend more time counterarguing outgroup than in-group criticism. Even though group members may disagree with out-group criticism as well as in-group criticism, critical comments from out-group sources are viewed as less constructive (Hornsey \& Imani, 2004; Hornsey, Oppes, \& Svensson, 2002) and thus are likely to be closely scrutinized and counterargued.

People usually pursue more than one goal and they usually do so with limited time available. When time is limited, people prioritize the goal that is most important to them, which may undermine the pursuit of less important goals (Schmidt $\&$ DeShon, 2007). Assuming that the goal of protecting group identity is an important goal for group members, the ISE should lead to counterarguing even at the cost of completing individual work.

A second implication of viewing the ISE as motivated is that attaining the goal of protecting the group identity by other means should reduce counterarguing (cf. Kruglanski et al., 2015; Kruglanski \& Kopetz, 2009). An effective means to protect group identity is extolling group virtues in an unrelated but important domain (group affirmation; Sherman et al., 2007; cf. Cohen \& Sherman, 2014; Steele, 1988). Since people are generally quite frugal with their limited goal-striving resources (Carver \& Scheier, 1990; Muraven, 2012), affirmed group members should allocate their resources to other goals such as their work.

\section{The Present Research}

We tested the prediction that out-group criticism leads group members to spend their limited time counterarguing, thereby reducing their performance on an unrelated task. In Experiment 1 , we sought to establish this effect. We then made counterarguing costlier by making the secondary task intrinsically rewarding (Experiment 2) or incentivizing the task (Experiment 3). Moreover, Experiment 2 extended our findings to another ISE manipulation in another intergroup context. In Experiments 4 and 5, we tested whether the observed behavioral ISE was motivated by defensiveness. To this end, we manipulated whether group members had the opportunity to attain their goal by an alternative means, group affirmation.

\section{Experiment I: Do Group Members Counterargue Instead of Getting Their Work Done?}

\section{Method \\ Participants and Design}

One hundred-eighteen University of Wyoming (UW) students (81 female, $M_{\mathrm{age}}=19.5$ ) participated for course credit. Sample size provided sufficient power $(1-\beta>.80)$ to detect a smallto-medium effect. Participants were randomly assigned to an in-group or an out-group comment source condition.

\section{Comment}

The comment criticized a lack of culture and diversity among Wyoming students (Online Supplementary Material 1). Wyoming is sparsely populated, has no large cities, and is ethnically homogeneous (U.S. Census, 2016). The comment thus may constitute a fair criticism. All participants received this message, which was attributed either to a UW student (in-group source) or to a student from Colorado State University (CSU; out-group source), a geographically proximal rival school.

\section{Procedure}

Participants received written instructions that the study examined UW and CSU students' knowledge and skills. Participants would work on a trivia task, read past participants' comments, and then write about their own opinions. In a second task, their goal would then be to solve as many anagrams as possible. Critically, we introduced a time limit, so that participants had to decide between responding to the comment and completing the anagram task. According to our earlier reasoning, prioritizing their responses would indicate a motivated behavior.

Participants then read the comment that was attributed either to the in-group source or to the out-group source. After reading the comment, participants could write about whether the comment was accurate. Instructions indicated they could write as much as they wanted and use the remaining time for the anagram task. The screen displayed a clock counting down from $5 \mathrm{~min}$.

After composing this response, participants received further instructions and worked on 20 anagrams. Participants had to enter the correct solution to advance to the next item. The computer recorded the time spent on each item and terminated the tasks after $5 \mathrm{~min}$. Participants provided demographic information and were debriefed. 
Table I. Intercoder Agreement and Reliability (Experiments I-5) and Comment Examples (Experiment I).

\begin{tabular}{|c|c|c|c|c|c|c|c|c|c|c|c|c|}
\hline \multirow[b]{2}{*}{ Coding Category } & \multirow[b]{2}{*}{ Rating Scale } & \multicolumn{2}{|c|}{ Experiment I } & \multicolumn{2}{|c|}{ Experiment 2} & \multicolumn{2}{|c|}{ Experiment 3} & \multicolumn{2}{|c|}{ Experiment 4} & \multicolumn{2}{|c|}{ Experiment 5} & \multirow{2}{*}{$\begin{array}{c}\text { Comment } \\
\text { Example (From } \\
\text { Experiment I) }\end{array}$} \\
\hline & & $\begin{array}{l}\text { Agreement } \\
(\%)\end{array}$ & $\kappa$ & $\begin{array}{l}\text { Agreement } \\
(\%)\end{array}$ & $\kappa$ & $\begin{array}{l}\text { Agreement } \\
(\%)\end{array}$ & $\kappa$ & $\begin{array}{c}\text { Agreement } \\
(\%)\end{array}$ & $\kappa$ & $\begin{array}{l}\text { Agreement } \\
(\%)\end{array}$ & $\kappa$ & \\
\hline $\begin{array}{l}\text { Agreement } \\
\text { with comment }\end{array}$ & $\begin{array}{l}\text { I: Agree to } \\
\text { 3: disagree }\end{array}$ & 86 & .74 & 77 & .60 & 85 & .75 & 67 & .51 & 84 & .75 & $\begin{array}{l}\text { "I agree with this } \\
\text { statement. It is } \\
\text { discouraging" }\end{array}$ \\
\hline $\begin{array}{l}\text { Derogated out- } \\
\text { groups } \\
\text { outside of } \\
\text { Wyoming }\end{array}$ & $\begin{array}{l}\text { I: Yes } \\
\text { 0: No }\end{array}$ & 89 & .44 & 89 & .62 & 96 & .68 & 90 & .49 & 96 & .43 & $\begin{array}{l}\text { "I have met my } \\
\text { fair share of } \\
\text { students from } \\
\text { Colorado who } \\
\text { are less } \\
\text { cultured than } \\
\text { students from } \\
\text { Wyoming" }\end{array}$ \\
\hline $\begin{array}{l}\text { Criticized } \\
\text { commenter }\end{array}$ & $\begin{array}{l}\text { I: Yes } \\
\text { 0: No }\end{array}$ & 95 & .81 & 84 & .69 & 88 & .62 & 87 & .51 & 89 & .35 & $\begin{array}{l}\text { "I think that } \\
\text { whoever made } \\
\text { that comment } \\
\text { is the one who } \\
\text { is close } \\
\text { minded" }\end{array}$ \\
\hline
\end{tabular}

\section{Results}

A coder blind to condition and the hypotheses scored all responses on four dimensions and a second coder scored $75 \%$ of the responses to provide intercoder reliability (Table 1; Online Supplementary Material 2). Coder 1 scores were analyzed (Table 2).

Participants in both conditions equally disagreed with the comment, praised the in-group, and criticized the out-group. Consistent with the ISE, responses were more likely to criticize the commenter in the out-group than in the in-group source condition. As predicted, participants in the out-group source condition spent more time responding, less time working, and correctly solved fewer anagrams than participants in the ingroup source condition.

\section{Experiment 2: Does the Behavioral ISE Generalize?}

Despite the support for our hypotheses, Experiment 1 used the specific intergroup context of two rival schools. We therefore sought to extend our findings to two larger groups (i.e., European students vs. U.S. American students). Moreover, there were no actual benefits or costs tied to anagram performance in Experiment 1. Although participants generally seemed motivated to perform well, they might simply be less interested in solving anagrams than responding to comments. We therefore used an intrinsically rewarding task (i.e., watching a funny video). Lastly, we assume that the observed behavioral effects reflect the classic ISE. To test this assumption directly, we included classic ISE self-report measures (adapted from Hornsey \& Imani, 2004).

\section{Method}

\section{Participants and Design}

We set the minimum sample size to equal Experiment 1 and recruited 163 University of Konstanz students $\left(M_{\text {age }}=21.33\right.$, 124 female) for course credit or $€ 3$. Eight participants failed the comment source manipulation check and two participants experienced computer failure, leaving $N=153$. Participants were randomly assigned to an in-group or an out-group comment source condition.

\section{Procedure}

Procedures were the same as in Experiment 1 with the following exceptions.

First, we developed a cover task and a critical comment about Europeans with a University of Konstanz student. Participants answered trivia questions on the latest trends and popular culture (Online Supplementary Material 3). Participants then received a critical comment describing Europeans as old-fashioned and arrogant (Online Supplementary Material 4), which was attributed either to a previous participant from the United States (out-group condition) or Europe (in-group condition). 
Table 2. Means of Dependent Measures by Group Condition and Inferential Tests (Experiment I).

\begin{tabular}{|c|c|c|c|c|c|c|}
\hline & In-Group & Out-Group & $t(116)$ & $p$ & $d$ & $95 \% \mathrm{Cl}$ of $d$ \\
\hline Time spent on anagram task (s) & 203.91 (52.1I) & $164.80(69.32)$ & 3.47 & $<.001$ & .64 & {$[0.27,1.01]$} \\
\hline Anagrams solved per minute & $1.69(1.07)$ & $2.23(4.13)$ & 0.80 & .425 & -.15 & {$[-0.51,0.21]$} \\
\hline Agreement with comment & $1.48(0.60)$ & $1.57(0.73)$ & 0.69 & .494 & -.13 & {$[-0.49,0.23]$} \\
\hline Praised in-group & $0.57(0.50)$ & $0.59(0.50)$ & 0.21 & .832 & .04 & {$[-0.32,0.40]$} \\
\hline$n$ & 60 & 58 & & & & \\
\hline
\end{tabular}

Note. Standard deviations are in parentheses. Greater $d$ values indicate a greater intergroup sensitivity effect. $\mathrm{Cl}=$ confidence interval.

Table 3. Comment Examples (Experiment 2, Translated).

\begin{tabular}{ll}
\hline Coding Category & Comment Example \\
\hline $\begin{array}{l}\text { Agreement with comment } \\
\text { Praised in-group as open minded }\end{array}$ & "The comment was appropriate" \\
$\begin{array}{l}\text { Derogated out-groups outside of Europe } \\
\text { Criticized commenter }\end{array}$ & $\begin{array}{l}\text { "As it is, I see far greater problems in America than in Europe" } \\
\text { "This obviously sounds like an American who has absolutely no clue what she is talking about" }\end{array}$ \\
\hline
\end{tabular}

Next, participants indicated where the commenter was from (as a manipulation check) and completed an 8-item message threat scale (e.g., "To what extent do you think this comment is threatening?" $1=$ not at all to $7=$ very much) and a 3-item message motive scale (e.g., "To what extent do you think the comment was constructive?" $1=$ not at all to $7=$ very much).

Lastly, participants read about the video rating task before writing their response to the comment. Specifically, participants' goal was to watch and rate a funny video for a pretest. After completing their comment, participants spent the remaining time watching an Asterix cartoon clip, which is popular in Germany. Participants then rated how funny they found the video and how much they liked it $(1=$ not at all to $10=a$ lot $)$. Although watching the video was fun, it also constitutes work because participants were allegedly helping us pretest materials. Participants had 6 min in total for both tasks.

\section{Results and Discussion}

Responses (Table 3) were scored (Table 1) and analyzed (Table 4) as in Experiment 1. Participants across both conditions were equally likely to praise the in-group. Participants in the out-group source condition agreed with the comment less and were more likely to criticize the out-group than participants in the in-group source condition. As in Experiment 1, participants were more likely to criticize the out-group commenter than the in-group commenter. Moreover, participants in the out-group source condition spent more time responding to the comment and marginally less time watching the video than in the in-group source condition. The behavioral ISE thus generalizes across intergroup contexts. The observed effects were somewhat weaker than in Experiment 1, potentially due to the intrinsically motivating video task.

Message threat $(\alpha=.81)$ and message motive $(\alpha=.71)$ ratings were combined into single indexes. Participants rated the out-group comment as being more threatening and less constructive than the in-group comment. The observed behavioral consequences thus reflect the ISE.

\section{Exploratory Analyses: Moderation by Video Ratings}

To assess whether the weaker behavioral ISE was due to the intrinsically rewarding secondary task, we probed comment source effects on anagram performance at different levels of video ratings $(\alpha=.91)$, using Johnson-Neyman tests in the PROCESS macro (Hayes, 2013). Video ratings did not differ between conditions. The source effect was significant at moderate to low video ratings (below 5.92, $p \mathrm{~s}<.05$ ) and nonsignificant for higher ratings $(5.92-6.40, p \mathrm{~s}>.05$, above $6.40, p \mathrm{~s}>$ .15). Participants who found the video less funny spent more time responding to the out-group but not the in-group comment, ${ }^{1}$ indicating that the attractive secondary task indeed reduced the behavioral ISE.

\section{Experiment 3: Does the Behavioral ISE Reflect Goal Prioritization?}

We next introduced a different consequence to participants, namely, a potential financial reward for anagram task performance. We further assessed how important performing well (i.e., goal commitment) and defending their group (i.e., group identification) was to participants. Theory (Hogg, 2016) would suggest that highly identified participants care the most about 
Table 4. Means of Dependent Measures by Group Condition (Experiment 2).

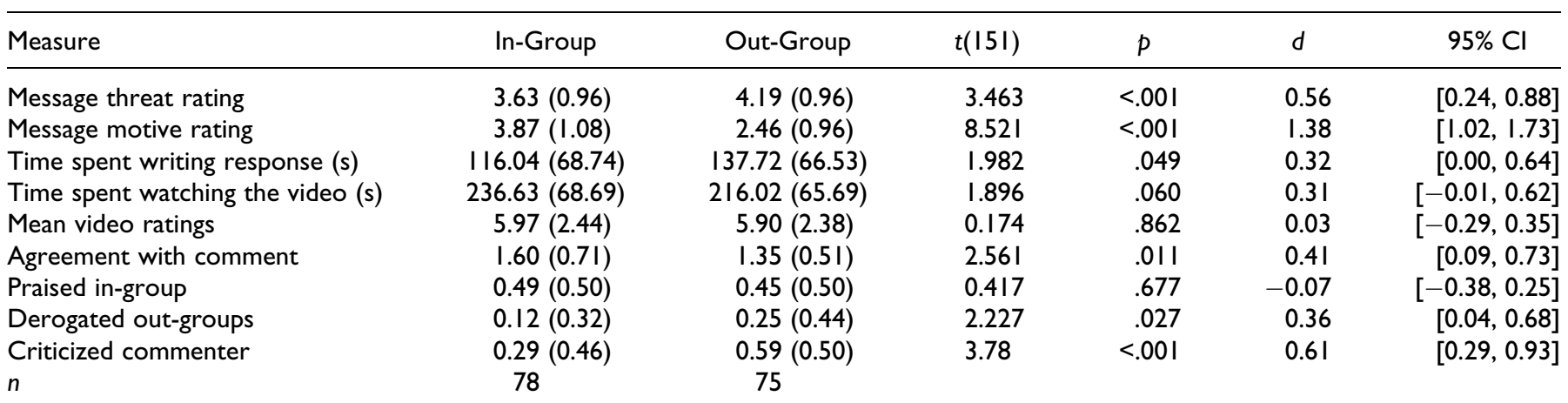

Note. Standard deviations are in parentheses. Greater $d$ values indicate a greater intergroup sensitivity effect. $\mathrm{Cl}=$ confidence interval.

Table 5. Means of Dependent Measures by Group Condition (Experiment 3).

\begin{tabular}{|c|c|c|c|c|c|c|}
\hline Measure & In-Group & Out-Group & $t(12 I)$ & $p$ & $d$ & $95 \% \mathrm{Cl}$ of $d$ \\
\hline Time spent writing response (s) & II4.6I (56.64) & $123.28(66.4 \mid)$ & 0.78 & .438 & .14 & {$[-.21, .49]$} \\
\hline Time spent on anagram task (s) & I 78.69 (56.28) & I 70.45 (65.44) & 0.75 & .456 & .14 & {$[-.22, .46]$} \\
\hline Anagrams solved per minute & $1.99(1.62)$ & $1.64(1.27)$ & 1.32 & .191 & .24 & {$[-.12, .59]$} \\
\hline Agreement with comment & $1.62(0.64)$ & $1.47(0.61)$ & 1.38 & .171 & .25 & {$[-.11, .60]$} \\
\hline Praised in-group & $0.61(0.4 I)$ & $0.69(0.4 \mathrm{I})$ & 1.07 & .289 & .19 & {$[-.16, .55]$} \\
\hline$n$ & 61 & 62 & & & & \\
\hline
\end{tabular}

Note. Standard deviations are in parentheses. Greater $d$ values indicate a greater intergroup sensitivity effect. $\mathrm{Cl}=$ confidence interval.

the group and should be most likely to prioritize defending their group over performing well, even at a potential financial cost.

\section{Method}

\section{Participants and Design}

We set minimum sample size to equal Experiment 1 and recruited 129 UW students $\left(M_{\text {age }}=20.5\right)$ for course credit and potential lottery participation. The computer failed to record data from five participants and one participant refused to participate in the lottery, leaving $N=123$. Participants were randomly assigned to an in-group or an out-group comment source condition.

\section{Procedure}

Procedures were the same as in Experiment 1 with the lottery description at the beginning. Participants were told they would receive one lottery ticket for each solved anagram to enter the drawing of a US\$30 Amazon gift card. After the anagram task, participants completed a 4-item group identification measure (e.g., "Being a UW student is an important reflection of who I am." 1 = strongly disagree to $7=$ strongly agree) and a 4 item measure to assess task commitment (e.g., "How committed were you to performing well on the anagram task?" $1=$ not at all to 7 = very much; adapted from Klein, Cooper, Molloy,
\& Swanson, 2014). The lottery winner was drawn and contacted at the study conclusion.

\section{Results and Discussion}

Scores by two coders were averaged (Table 1) and analyzed (Table 5). As in Experiment 1, participants across conditions equally disagreed with the comment, praised the in-group, and criticized the out-group. Consistent with the ISE, participants were more likely to criticize the out-group commenter than the in-group commenter.

Comment source did not affect response time or time spent on the anagram task. Individuals in the out-group source condition solved marginally fewer anagrams than individuals in the in-group source condition. The introduction of the lottery thus further weakened the behavioral ISE, although the effects were within the $95 \%$ confidence intervals (CIs) observed in Experiment 1.

\section{Exploratory Analyses: Moderation by Identification and Goal Commitment}

We next averaged the identification $(\alpha=.81)$ and commitment items $(\alpha=.90)$ and probed comment source effects on anagram performance at different levels of identification and commitment. The source effect was not significant at low levels but marginal or significant at moderate to high levels of either 
identification (above 4.25, $p$ s $<.07$ ) or commitment (above $3.73, p \mathrm{~s}<.05){ }^{2}$ The behavioral ISE was thus stronger among participants who were more motivated to defend the group and wanted to perform well. This suggests that identity concerns motivate defending the group and that this defense may even hinder important goals. Parallel tests revealed no significant effects of comment source on response time or on anagram time for any level of identification or commitment.

\section{Experiment 4: Does Defense Goal Attainment Moderate the Behavioral ISE Effect?}

Experiment 3 demonstrated that the behavioral ISE is stronger among highly identified group members who want to protect the group. But we have not provided causal evidence that these persistent behaviors serve the goal of protecting group identity. If so, group members' willingness to counterargue an outgroup comment could be reduced by protecting the group in other ways such as extolling another important group value. Such group affirmation (Sherman et al., 2007) would then allow individuals to use their limited time to pursue other tasks (cf. Adams, Tormala, \& O'Brien, 2006). We therefore predicted that an opportunity to affirm the group reduces counterarguing out-group criticism.

\section{Method}

\section{Participants and Design}

Sample size was determined by a power analysis $(1-\beta=.80)$ for detecting the predicted interaction, assuming the effect size observed in Experiment 1; 130 (88 female) UW students $\left(M_{\mathrm{age}}=20.5\right)$ participated for course credit. The computer failed to record data from two participants, leaving $N=128$. Participants were randomly assigned to a 2 (group: in-group comment vs. out-group comment) $\times 2$ (affirmation: yes vs. no) between-participant design.

\section{Group Affirmation}

Participants were asked to rank 10 values (e.g., work ethic; Online Supplementary Material 5) by importance to their group $(1=$ most important to $10=$ least important $)$. Several of these values reflect aspects of Zane Grey's "Code of the West" and the state's "Cowboy Ethics." In the affirmation conditions, participants wrote why they considered their top-ranked value to be important to UW students, thereby affirming their positive group identity. In the no-affirmation condition, participants wrote why their lowest ranked value might be important to students at another university, giving three specific examples (adapted from Sherman et al., 2007).

\section{Procedure}

The procedures were the same as in Experiment 1, with the above-mentioned affirmation manipulation taking place immediately after the initial cover story and before reading the comment. Finally, participants completed the group identification measure (Experiment 3).

\section{Results and Discussion}

The dependent measures were submitted to 2 (comment source: in-group vs. out-group) $\times 2$ (affirmation: yes vs. no) analyses of variance (ANOVAs; Table 6). All omitted test results are nonsignificant, $F \mathrm{~s}(1,124)<1.11, p \mathrm{~s} \geq .30$.

Responses were scored as in Experiment 3 (Table 1). Participants agreed with the comment less when made by an outgroup than an in-group member, $F(1,124)=4.43, p=.042$, $d=.39$. Replicating previous results, participants were more likely to say something negative about the out-group commenter than the in-group commenter, $F(1,124)=5.23, p=.024$, $d=.41$. However, there were no effects of affirmation condition. Thus, the ISE was not significantly reduced by affirmation.

The predicted Comment Source $\times$ Affirmation interaction emerged on time spent composing a response, $F(1,124)=$ $5.30, p=.023, d=.41$; the time spent on the anagrams, $F(1,124)=4.95, p=.028, d=.40$; and the number of solved anagrams, $F(1,124)=4.14, p=.044, d=.37$. Without affirmation, individuals receiving an out-group comment spent marginally less time responding, spent marginally more time on the anagrams, and performed nonsignificantly worse than individuals receiving the comment from the in-group. With affirmation, we observed no significant differences. In sum, when individuals had attained their group identity goal via affirming an important value, they no longer demonstrated the behavioral ISE.

\section{Exploratory Analyses With Identification}

As in Experiment 3, we averaged the identification scores $(\alpha=$ $.79)$ and probed the Comment Source $\times$ Affirmation interaction at different levels of identification. The observed interaction was significant $(p s<.05)$ for highly identified participants (above 3.857 for response times; above 3.967, for time spent on the anagram task; from 3.357 to 5.225 , for anagram performance). In the no-affirmation condition, the source effect was stronger for higher levels of identification. Those who cared more about their group and could not affirm their group identity thus showed the strongest behavioral ISE. ${ }^{3}$

\section{Experiment 5: Does the Affirmation Manipulation Matter?}

In Experiment 4, participants in the no-affirmation condition wrote about values important to an unspecified out-group member, instead of a "typical college student" (Sherman et al., 2007; Study 1). Reference to an out-group could make intergroup conflict salient, thereby increasing the ISE. Alternatively, taking an out-group's perspective can reduce the differentiation between in-group and out-group (Galinsky \& Moskowitz, 2000), thereby diminishing the ISE. To rule out 


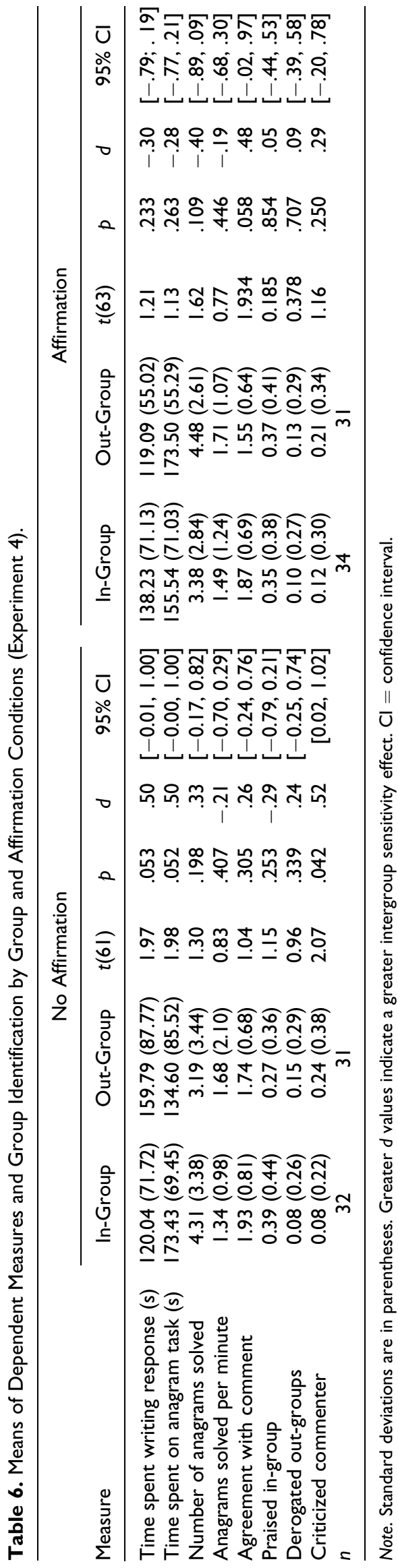

these potential alternative explanations, we conducted Experiment 5 using Sherman, Kinias, Major, Kim, and Prenovost's (2007; Study 2) manipulation. We moreover used a different out-group (University of Colorado at Boulder students) to increase the generalizability of our findings.

\section{Method}

\section{Participants and Design}

We set minimum sample size to equal Experiment 4; 134 (82 female) UW students $\left(M_{\text {age }}=19.43\right)$ participated for course credit. Participants were randomly assigned to a 2 (group: ingroup comment vs. out-group comment) $\times 2$ (affirmation: yes vs. no) between-participant design.

\section{Procedure}

The procedures were identical to Experiment 4, with two exceptions: Participants in the no-affirmation condition also ranked the values (Online Supplementary Material 6) and then continued the experiment without writing an essay (Sherman et al., 2007; Study 2). Moreover, we changed the out-group source to a student form the University of Colorado at Boulder, a proximal and highly prestigious school.

\section{Results and Discussion}

The dependent measures were submitted to 2 (comment source: in-group vs. out-group) $\times 2$ (affirmation: yes vs. no) ANOVAs (Table 7). All omitted test results are nonsignificant, $F \mathrm{~s}(1,130)$ $<2.30, p \mathrm{~s} \geq .13$.

Scored responses (Table 1; the computer failed to record one participant response) replicated Experiment 4. Participants in the out-group comment source conditions agreed less with the comment, $F(1,129)=6.21, p=.014, d=.44$, and were more likely to criticize the commenter, $F(1,129)=6.44, p=.012$, $d=.43$, than participants in the in-group comment source conditions. Again, this ISE was not significantly reduced by affirmation. Comment source did not impact criticizing the out-group or praising the in-group.

Unexpectedly, participants in the affirmation conditions spent less time on the anagram task, $F(1,130)=4.04, p=$ $.046, d=.35$, and marginally more time responding to the comment, $F(1,130)=3.60, p=.060, d=.33$. Writing the affirmation essay may have facilitated writing lengthy responses to the comment.

The predicted Comment Source $\times$ Affirmation interactions for the time spent responding to the comment, the time spent on the anagrams, and the number of anagrams solved were all not significant, all $F \mathrm{~s}(1,130)<1.89, p>.170, d<.24$. Exploratory analyses with identification $(\alpha=.75)$ did not show any regions of significance. Despite the failure to replicate the significant interactions from Experiment 4, the descriptive results were in the predicted direction: The observed effect sizes in the no-affirmation condition were within the range observed in Experiments 1-3 and 4 (no-affirmation condition). The 


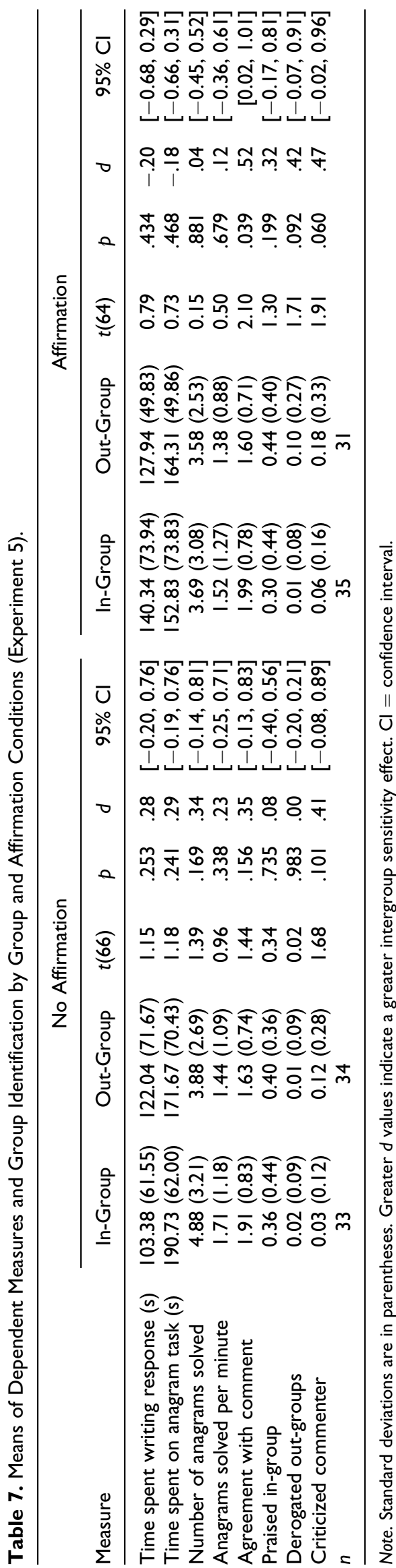

no-affirmation instructions thus did not systematically alter the behavioral ISE. In the affirmation condition, response time and time on task effects were reversed, and the performance effect was small.

We used the same sample size as in Experiment 4, which proved insufficient to detect the smaller interaction effects in Experiment 5. We thus conducted meta-analyses to probe the expected main effects and interaction effects across studies.

\section{Meta-Analysis}

Observed effect sizes varied across experiments, and some predicted effects were nonsignificant. We therefore conducted meta-analyses across our five studies including only the no-affirmation conditions in Experiments 4 and 5. We used a fixed effects model with inverse variance weighting (Lipsey \& Wilson, 2001; Online Supplementary Material 7). This approach assumes substantially similar studies and places greater weight on effect sizes with smaller standard errors. Criticism of the commenter, $M=.50,95 \%$ CI [0.33, $0.68]$; response time, $M=.36,95 \%$ CI [0.19, 0.54]; time on task, $M=.36,95 \% \mathrm{CI}[0.19,0.53]$; and anagram performance, $M=.38,95 \%$ CI $[0.17,0.58]$, all reliably differed between comment source conditions. The ISE therefore has robust behavioral consequences. ${ }^{4}$

Interestingly, across all studies, participants in the out-group source condition also reliably agreed less with the comment, $M=.22,95 \% \mathrm{CI}[0.05,0.40]$, and derogated the out-group more, $M=.20,95 \%$ CI $[0.03,0.37]$, than participants in the in-group source condition. No effects of comment source on anagrams solved per minute, $M=.04,95 \%$ CI $[-0.17$, $0.24]$, or praising the in-group, $M=.01,95 \%$ CI $[-0.16$, 0.18 ], emerged.

We moreover expected that group affirmation would relieve group members from the need to counterargue outgroup criticism. Although both Experiment 4 and Experiment 5 show this expected pattern, only Experiment 4 produced significant interactions. We therefore conducted meta-analyses on the behavioral measures for Experiments 4 and 5 (Lipsey \& Wilson, 2001; Online Supplementary Material 8). As expected, effect sizes for the comment source were homogeneous within affirmation conditions and within noaffirmation conditions, all $Q_{\text {within }}(2)<1.30, p s>.50$, but significantly heterogeneous between the affirmation and no-affirmation conditions, all $Q_{\text {between }}(1)>4.60, p s<.04$. In the no-affirmation conditions, the behavioral ISE was reliable for response time, $M=.38,95 \%$ CI [0.04, 0.73], and time on task, $M=.39,95 \%$ CI [0.04, 0.73], and marginal for performance, $M=.33,95 \%$ CI $[-0.01,0.68]$. In the affirmation conditions, all these effects were nonsignificant, $M_{\text {response time }}=-.25,95 \%$ CI $[-0.59,0.10]$; $M_{\text {time-on-task }}=-.23,95 \% \mathrm{CI}[-0.58,0.11]$; and $M_{\text {performance }}=$ $-.20,95 \%$ CI $[-0.55,0.14]$. This indicates that group affirmation moderates the behavioral ISE. 


\section{General Discussion}

We argued that threatening out-group criticism motivates group members to allocate their time and effort to protecting their group identity, thereby undermining performance on other tasks. In line with this motivated collective defensiveness perspective, out-group criticism consistently led participants to spend more time counterarguing and to more strongly criticize the commenter than the same criticism from an in-group member. Additionally, participants showed more disagreement and out-group derogation in response to the out-group comment than the in-group comment, although these effects were small and only reliable in Experiment 2 and the meta-analysis.

These behaviors were goal directed: Participants spent their limited time on counterarguing instead of completing their work (Experiments 1-4). Increasing the cost by making work fun (Experiment 2) or tying performance to a potential monetary incentive (Experiment 3) weakened this effect somewhat, although it remained reliable in our meta-analysis. Once individuals had attained their goal of defending the group via group affirmation, they did get their work done (Experiments 4, metaanalysis), although this moderation effect was small and nonsignificant in Experiment 5. The source effect on performance was generally stronger among highly identified group members who care most about defending their group.

\section{Contributions and Implications}

We demonstrate that the ISE leads to persistent goal pursuit including expanding effort, investing limited time, and disengaging after attainment. Since attitude-intention (Armitage \& Conner, 2001) and intention-action (Sheeran \& Webb, 2016) relations are generally modest, this is the crucial contribution of our motivated collective defensiveness perspective.

We moreover identified boundary conditions of the behavioral ISE. Effects were weaker among low identifiers and when rewards were attached to the alternative task. Lastly, the pattern of results was reversed when the goal of protecting group identity had been attained through affirmation.

The behavioral ISE may have important practical implications. In particular, group performance may suffer when members spend their limited resources responding to out-group criticism. Additionally, criticism from out-group members seems to be met with personal attacks that could lead to further distrust and resentment. However, it is possible that including group affirmations in the comment helps reduce defensive reactions and increase persuasion. Testing these applications of the behavioral ISE is more important than ever in a society that is increasingly divided along partisan lines.

\section{Generalizability and Limitations}

The observed behavioral consequences were evident across studies, but varied in strength, and all studies included student samples. Future research should therefore use samples that are even bigger and more representative (Thürmer \& McCrea, in press). As discussed above, these studies need to ensure high group identification, either by using intergroup contexts with a high personal relevance (such as abortion rights vs. restrictions advocates) or by using strong experimental manipulations in a minimal group paradigm.

The stereotype threat literature (Schmader, Johns, \& Forbes, 2008) further suggests that the threat of an out-group comment may reduce cognitive resources such as working memory capacity (e.g., Schmader \& Johns, 2003; Study 3). This prediction is consistent with our motivated defensiveness perspective: Unfulfilled (defense) goals remain cognitively active (Rothermund, 2003; Zeigarnik, 1927) and may therefore impair cognitive resources. This is evident in Experiment 3, where we observed no comment source effect on time on task but reduced performance in the out-group source condition. However, anagrams solved per minute neither differed in any experiment nor across all studies in the meta-analysis (average effect $M=.04$ ), as would be expected if cognitive resources were systematically diminished. Further research is needed to integrate our motivated collective defensiveness account with the abundant literature on stereotype threat and to test the effect of unfulfilled defensiveness goals on cognitive resources.

Lastly, participants showed the ISE in their written responses despite group affirmation. In line with this finding, bystanders show the ISE because intergroup criticism violates social conventions (Sutton, Elder, \& Douglas, 2006). However, it is questionable whether people act on such general norm violations. The observed moderators, affirmation and group identification, suggest that defending group identity is the main motivation for the behavioral ISE.

In conclusion, group members are motivated to defend their group against the perceived threat of out-group criticism. This is bad news for efforts to foster constructive dialogue between groups. The good news is that briefly extolling an important group value may go a long way toward increasing accepting of criticism and the productive allocation of group resources.

\section{Acknowledgments}

We thank the members of the Social Psychology and Motivation Lab at the University of Konstanz for their helpful comments on earlier versions of this manuscript and Amanda Still, Andrew Olson, Jordan Kucera, Mary Gokanakonda, and Fayth Walbridge at the University of Wyoming as well as Carolin Roth and Hans Wahl at the University of Konstanz for assistance with data collection.

\section{Declaration of Conflicting Interests}

The author(s) declared no potential conflicts of interest with respect to the research, authorship, and/or publication of this article.

\section{Funding}

The author(s) received no financial support for the research, authorship, and/or publication of this article.

\section{Supplemental Material}

The supplemental material is available in the online version of the article. 


\section{Notes}

1. The moderator was measured after the dependent measures; watching the video, writing the response, or evaluating the message could thus have potentially impacted the video evaluations. Regression analyses did not support this alternative explanation, all $\beta \mathrm{s}<|.25|, p \mathrm{~s}>18$.

2. Regression analyses showed that anagram performance did predict commitment, $\beta=.29, p=.001$, but condition did not, $\beta=.04$, $p=.659$. Neither performance nor condition predicted group identification, all $\beta \mathrm{s}<|.37|, p \mathrm{~s}>.700$.

3. Regression analyses did not support reverse causation of the moderator, $\beta \mathrm{s}<|.11|, p \mathrm{~s}>.300$.

4. The effects held when only including Experiments $1-3$ in the meta-analyses.

\section{References}

Adams, G., Tormala, T. T., \& O'Brien, L. T. (2006). The effect of selfaffirmation on perception of racism. Journal of Experimental Social Psychology, 42, 616-626. doi:10.1016/j.jesp.2005.11.001

Ariyanto, A., Hornsey, M. J., \& Gallois, C. (2010). United we stand: Intergroup conflict moderates the intergroup sensitivity effect. European Journal of Social Psychology, 40, 169-177. doi:10. 1002/ejsp.628

Armitage, C. J., \& Conner, M. (2001). Efficacy of the theory of planned behavior: A meta-analytic review. British Journal of Social Psychology, 40, 471-499.

Baumeister, R. F., \& Scher, S. J. (1988). Self-defeating behavior patterns among normal individuals: Review and analysis of common self-destructive tendencies. Psychological Bulletin, 104, 3-22. doi: 10.1037/0033-2909.104.1.3

Baumeister, R. F., Vohs, K. D., \& Funder, D. C. (2007). Psychology as the science of self-reports and finger movements: Whatever happened to actual behavior? Perspectives on Psychological Science, 2, 396-403. doi:10.1111/j.1745-6916.2007.00051.x

Brander, T. V., \& Hornsey, M. J. (2006). Intergroup sensitivity effect and the war in Iraq: A case of attitudes and intentions diverging. Australian Journal of Psychology, 58, 166-172. doi:10.1080/ 00049530600940265

Branscombe, N. R., Ellemers, N., Spears, R., \& Doosje, B. (1999). The context and content of social identity threat. In N. Ellemers, R. Spears, \& B. Doosje (Eds.), Social identity: Context, commitment, content (pp. 35-58). Oxford, England: Blackwell Science.

Brewer, M. B., \& Gardner, W. (1996). Who is this "We"? Levels of collective identity and self representations. Journal of Personality and Social Psychology, 71, 83-93. doi:10.1037/0022-3514.71.1.83

Carver, C. S., \& Scheier, M. F. (1990). Origins and functions of positive and negative affect: A control-process view. Psychological Review, 97, 19-35.

Cohen, G. L., \& Sherman, D. K. (2014). The psychology of change: Self-affirmation and social psychological intervention. Annual Review of Psychology, 65, 333-371. doi:10.1146/annurev-psych010213-115137

Crocker, J., \& Park, L. E. (2004). The costly pursuit of self-esteem. Psychological Bulletin, 130, 392-414. doi:10.1037/0033-2909. 130.3.392 de Hoog, N. (2013). Processing of social identity threats: A defense motivation perspective. Social Psychology, 44, 361-372. doi:10. 1027/1864-9335/a000133

Elder, T. J., Sutton, R. M., \& Douglas, K. M. (2005). Keeping it to ourselves: Effects of audience size and composition on reactions to criticisms of the ingroup. Group Processes \& Intergroup Relations, 8, 231-244. doi:10.1177/1368430205053940

Esposo, S. R., Hornsey, M. J., \& Spoor, J. R. (2013). Shooting the messenger: Outsiders critical of your group are rejected regardless of argument quality. British Journal of Social Psychology, 52, 386-395. doi:10.1111/bjso.12024

Galinsky, A. D., \& Moskowitz, G. B. (2000). Perspective-taking: Decreasing stereotype expression, stereotype accessibility, and in-group favoritism. Journal of Personality and Social Psychology, 78, 708-724. doi:10.1037/0022-3514.78.4.708

Gollwitzer, P. M., Wicklund, R. A., \& Hilton, J. L. (1982). Admission of failure and symbolic self-completion: Extending Lewinian theory. Journal of Personality and Social Psychology, 43, 358-371. doi:10.1037/0022-3514.43.2.358

Hayes, A. F. (2013). Introduction to mediation, moderation, and conditional process analysis: A regression-based approach. New York, NY: Guilford.

Hogg, M. A. (2016). Social identity theory. In S. McKeown, R. Haji, \& N. Ferguson (Eds.), Understanding peace and conflict through social identity theory: Contemporary global perspectives (pp. 3-17). Cham, Switzerland: Springer International.

Hornsey, M. J. (2005). Why being right is not enough: Predicting defensiveness in the face of group criticism. European Review of Social Psychology, 16, 301-334. doi:10.1080/104632 80500436040

Hornsey, M. J., \& Esposo, S. (2009). Resistance to group criticism and recommendations for change: Lessons from the intergroup sensitivity effect. Social and Personality Psychology Compass, 3, 275-291. doi:10.1111/j.1751-9004.2009.00178.x

Hornsey, M. J., \& Imani, A. (2004). Criticizing groups from the inside and the outside: An identity perspective on the intergroup sensitivity effect. Personality and Social Psychology Bulletin, 30, 365-383. doi:10.1177/0146167203261295

Hornsey, M. J., Oppes, T., \& Svensson, A. (2002). "It's OK if we say it, but you can't": Responses to intergroup and intragroup criticism. European Journal of Social Psychology, 32, 293-307. doi: 10.1002/ejsp.90

Hornsey, M. J., Robson, E., Smith, J., Esposo, S., \& Sutton, R. M. (2008). Sugaring the pill: Assessing rhetorical strategies designed to minimize defensive reactions to group criticism. Human Communication Research, 34, 70-98. doi:10.1111/j.1468-2958.2007. 00314. $\mathrm{x}$

Hornsey, M. J., Trembath, M., \& Gunthorpe, S. (2004). "You can criticize because you care": Identity attachment, constructiveness, and the intergroup sensitivity effect. European Journal of Social Psychology, 34, 499-518. doi:10.1002/ejsp.212

Klein, H. J., Cooper, J. T., Molloy, J. C., \& Swanson, J. A. (2014). The assessment of commitment: Advantages of a unidimensional, target-free approach. Journal of Applied Psychology, 99, 222-238. doi:10.1037/a0034751 
Kruglanski, A. W., Jasko, K., Chernikova, M., Milyavsky, M., Babush, M., Baldner, C., .. . Pierro, A. (2015). The rocky road from attitudes to behaviors: Charting the goal systemic course of actions. Psychological Review, 122, 598-620. doi:10.1037/a0039541

Kruglanski, A. W., \& Kopetz, C. (2009). The role of goal systems in self-regulation. In E. Morsella, J. A. Bargh, \& P. M. Gollwitzer (Eds.), Oxford handbook of human action (pp. 350-367). New York, NY: Oxford University Press.

Lipsey, M. W., \& Wilson, D. B. (2001). Practical meta-analysis. Thousand Oaks, CA: Sage.

Morier, D., Bryan, A. E. B., \& Kasdin, L. (2013). The effects of group identity, group choice, and strength of group identification on intergroup sensitivity. Group Dynamics: Theory, Research, and Practice, 17, 14-29. doi:10.1037/a0030190

Muraven, M. (2012). Ego depletion: Theory and evidence. In R. M. Ryan (Ed.), The Oxford handbook of human motivation (pp. 111-126). Oxford, England: Oxford University Press.

Parker, A., \& Corasaniti, N. (2016, October 27). Some Donald Trump voters warn of revolution if Hillary Clinton wins. The New York Times. Retrieved from http://www.nytimes.com/2016/10/28/us/pol itics/donald-trump-voters.html

Rabinovich, A., \& Morton, T. A. (2010). Who says we are bad people? The impact of criticism source and attributional content on responses to group-based criticism. Personality and Social Psychology Bulletin, 36, 524-536. doi:10.1177/0146167210362980

Rothermund, K. (2003). Automatic vigilance for task-related information: Perseverance after failure and inhibition after success. Memory \& Cognition, 31, 343-352. doi:10.3758/BF03194392

Schmader, T., \& Johns, M. (2003). Converging evidence that stereotype threat reduces working memory capacity. Journal of Personality and Social Psychology, 85, 440-452. doi:10.1037/0022-3514. 85.3.440

Schmader, T., Johns, M., \& Forbes, C. (2008). An integrated process model of stereotype threat effects on performance. Psychological Review, 115, 336.

Schmidt, A. M., \& DeShon, R. P. (2007). What to do? The effects of discrepancies, incentives, and time on dynamic goal prioritization. Journal of Applied Psychology, 92, 928-941. doi:10.1037/00219010.92.4.928

Sheeran, P., \& Webb, T. L. (2016). The intention-behavior gap. Social and Personality Psychology Compass, 10, 503-518. doi:10.1111/ $\operatorname{spc} 3.12265$

Sherman, D. K., Kinias, Z., Major, B., Kim, H. S., \& Prenovost, M. (2007). The group as a resource: Reducing biased attributions for group success and failure via group affirmation. Personality and Social Psychology Bulletin, 33, 1100-1112. doi:10.1177/ 0146167207303027
Steele, C. M. (1988). The psychology of self-affirmation: Sustaining the integrity of the self. In L. Berkowitz (Ed.), Advances in experimental social psychology (Vol. 21, pp. 261-302). Waltham, MA: Academic Press.

Sutton, R. M., Elder, T. J., \& Douglas, K. M. (2006). Reactions to internal and external criticism of outgroups: Social convention in the intergroup sensitivity effect. Personality and Social Psychology Bulletin, 32, 563-575. doi:10.1177/0146167205282992

Tajfel, H., \& Turner, J. C. (1986). The social identity theory of intergroup behavior. In S. Worchel \& W. G. Austin (Eds.), Psychology of intergroup relations (2nd ed., Vol. 1, pp. 7-24). Chicago, IL: Nelson-Hall.

Thürmer, J. L., \& McCrea, S. M. (in press). Beyond motivated reasoning: Hostile reactions to critical comments from the outgroup. Motivation Science. doi: 10.1037/mot0000097

U.S. Census. (2016). QuickFacts: Wyoming. Retrieved April 05, 2017, from https://www.census.gov/quickfacts/table/PST045216/56

Zeigarnik, B. (1927). Das Behalten erledigter und unerledigter Handlungen. [Memory for completed and interrupted tasks]. Psychologische Forschung, 9, 1-85. doi:10.1007/bf02409755

\section{Author Biographies}

J. Lukas Thürmer is a postdoctoral researcher at the University of Konstanz. His research focuses on how individual and collective self-regulation enhances performance and may reduce defensive behaviors. His work has been published in several academic journals including the American Journal of Psychology, Journal of Behavioral Decision Making, and Frontiers in Human Neuroscience as well as a recent chapter in The psychology of planning in organizations: Research and applications.

Sean M. McCrea received his $\mathrm{PhD}$ from the Indiana University and is an associate professor at the University of Wyoming, Laramie. His research focuses on motivational and cognitive processes underlying defensive behaviors in a variety of contexts, particularly selfhandicapping behavior and protecting group identity. He frequently publishes in the leading journals of the field including the Journal of Personality and Social Psychology, Personality and Social Psychology Bulletin, and Psychological Science.

Baylee M. McIntyre received her BA from the University of Wyoming in 2015. Her thesis, which is part of this article, focused on the control of the behavioral costs of intergroup sensitivity through group affirmation.

Handling Editor: Kate Ratliff 